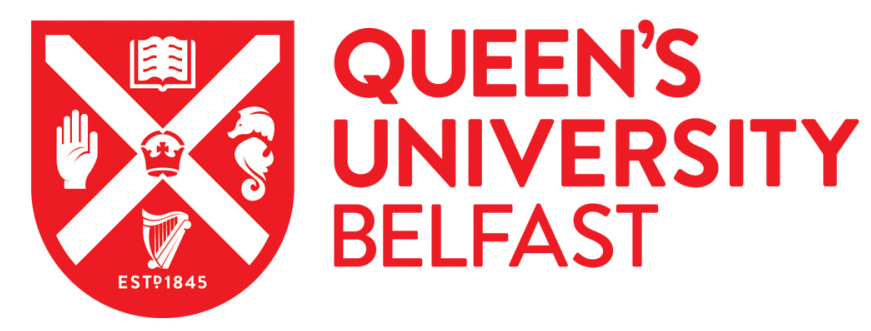

\title{
The Ghost in the Legal Machine Algorithmic Governmentality, Economy, and the Practice of Law
}

Harkens, A. (2018). The Ghost in the Legal Machine Algorithmic Governmentality, Economy, and the Practice of Law. Journal of Information, Communication \& Ethics in Society. https://doi.org/10.1108/JICES-09-2016-0038

Published in:

Journal of Information, Communication \& Ethics in Society

Document Version:

Peer reviewed version

Queen's University Belfast - Research Portal:

Link to publication record in Queen's University Belfast Research Portal

Publisher rights

(c) Emerald Publishing Limited 2017. This work is made available online in accordance with the publisher's policies. Please refer to any applicable terms of use of the publisher.

\section{General rights}

Copyright for the publications made accessible via the Queen's University Belfast Research Portal is retained by the author(s) and / or other copyright owners and it is a condition of accessing these publications that users recognise and abide by the legal requirements associated with these rights.

Take down policy

The Research Portal is Queen's institutional repository that provides access to Queen's research output. Every effort has been made to ensure that content in the Research Portal does not infringe any person's rights, or applicable UK laws. If you discover content in the Research Portal that you believe breaches copyright or violates any law, please contact openaccess@qub.ac.uk. 


\section{The Ghost in the Legal Machine: Algorithmic Governmentality, Economy, and the Practice of Law}

\section{Abstract}

Purpose - This paper investigates algorithmic governmentality - as proposed by Antoinette Rouvroy - specifically in relation to law. It seeks to show how algorithmic profiling can be particularly attractive for those in legal practice, given restraints on time and resources. It deviates from Rouvroy in two ways. Firstly, it argues that algorithmic governmentality does not contrast with neoliberal modes of government, in that it allows indirect rule through economic calculations. Secondly, that critique of such systems is possible, especially if the creative nature of law can be harnessed effectively.

Design/methodology/approach - This is a conceptual paper, with a theory-based approach, that is intended to explore relevant issues related to algorithmic governmentality as a basis for future empirical research. It builds on governmentality and socio-legal studies, as well as research on algorithmic practices and some documentary analysis of reports and public-facing marketing of relevant technologies.

Findings - This paper provides insights on how algorithmic knowledge is collected, constructed, and applied in different situations. It gives examples of how algorithms are currently used, and also how trends are developing. It demonstrates how such uses can be informed by socio-political and economic rationalities.

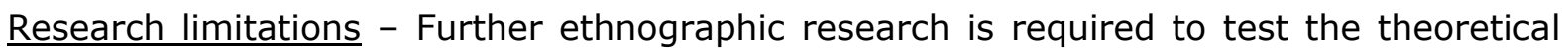
findings.

Originality/value - This paper takes up Rouvroy's question of whether we are at the end(s) of critique, and seeks to identify where such critique can be made possible. It also highlights the importance of acknowledging the role of political rationalities in informing the activity of algorithmic assemblages.

\section{Introduction}

Algorithmic governmentality is a term coined by Antoinette Rouvroy (2012) to describe new regimes of power brought forward by the 'computational turn', and the everincreasing prevalence of algorithms in daily life. Popular applications include the structuring of social media timelines, the provision of tailored music and film recommendations, and the filtering and dissemination of news articles. Each of these applications shares a common theme, in that they bring a structured order to the chaos of the online world - so that information becomes more easily digestible and manageable for the everyday user. 
However, algorithms also enable the profiling of these same users through data-mining practices, thus allowing a form of financial risk management aiming at "minimizing the uncertainty associated to human agency" (p.10). In this manner then, the chaos of worldly potentialities also becomes ordered and more easily digestible for those charged with the tasks of governing and decision-making, whether accurate or not (and if not, this threatens potentially dire consequences for the profiled individual). Algorithms are not fussy about whom they work for.

This paper focuses on a specific definition of 'governmentality' given by Foucault, and subsequent scholars. I will also attempt to demarcate points of differentiation between Rouvroy's thought, and my own, so as to prevent any confusion.

Foucault (2008, p. 186) describes the 'art of government' as the way in which one "conducts the conduct of men" or endeavours to "shape, guide or direct" the conduct of others (Rose, 1999, p.15). Miller and Rose (2008, p.15-16) have split this into two aspects: the first being rationalities, mentalities or "styles of thinking, ways of rendering reality thinkable in such a way that it [becomes] amenable to calculation and programming", which are rational in the sense that they privilege "systematic ways of thinking", such as the languages of economics and management, "over symbolic, mythical or poetic modes" (Dean, 2010, p.25); and the second, of human technologies or "assemblages of persons, techniques, institutions, instruments for the conducting of conduct." This article places algorithms firmly within the second aspect, as instruments of government, which hold the potential for distinctive effect based upon the governmental rationality with which they are employed, and the assemblages they are situated within.

This paper looks at one particular concept which has become more prominent in recent times, and relies on algorithms in order to work effectively: big data. Big data is at the forefront of aforementioned algorithmic risk management techniques, which enact what Antoinette Rouvroy (2012, p.143) refers to as data-behaviourism, or new ways of "producing knowledge [about future events] without considering the subject's psychological motivations, speeches or narratives, but rather relying on data."

Once this knowledge is collated and organised, it can be acted upon due to the belief in its 'objective' value. Certain areas have become particularly amenable to such practices, including online advertising, personal insurance, health (as evidenced by both the concepts of quantified self and genomics, whereby data scientists such as Jeff Hammerbacher seek to make medicine an "information game" (Lohr 2015, p. 163-164)), and crucially to this specific article, law and legal knowledge. 
Nevertheless, this paper takes a step away from Rouvroy's contention that algorithmic governmentality "contrasts with what we know about a neoliberal mode of government which produces the subjects it needs" (p.8). On the contrary, algorithms represent the ideal tools for a neoliberal form of economic management, entailing what Miller and Rose refer to as government at a distance (2008, p.16).

In addition, while Rouvroy is not interested in "whether algorithms produce 'valid' predictions or not" (p.143), this article argues that it is crucial to make any inaccuracies within algorithmic systems clear, so as to form the basis of critique. As algorithms become more prominent in legal systems, the creative nature of law is crucial in forming these critiques, so that the ghost in the legal machine (meaning here the discrete artificial 'intelligence' attributed to algorithms), is taken with a large pinch of salt - and the unintentional 'lock-in' of socio-legal norms can be prevented.

This paper is separated into five sections: The first provides a working definition for big data, to provide clarity in understanding; the second describes some of the practices involved in data collection for algorithmic techniques; the third deals directly with the process of algorithmic knowledge production, and the contradictions involved; the fourth looks at how algorithms contribute to neoliberal modes of government, specifically in the area of criminal justice; the fifth section discusses the dangers of allowing technological developments in the common law to drift by, without harnessing the creative nature of the law, to enable critique; and finally, a section of conclusions summarise what has been set out beforehand, limitations of this research as a conceptual paper, and suggest areas for future research.

\section{What is 'big data'?}

As Kitchin (2014, p.68) has stated, there is little consensus on the definition of big data, but some major themes are generally applicable: volume, velocity and variety. In other words, big data refers to the collection of massive data sets so quickly, and complex in variety, that traditional forms of analysis are insufficient. To make sense of these, intricate algorithms are applied that have the ability to carry out 'bottom-up' learning through data-mining processes, thus allowing emergent conclusions to be made, that are not necessarily immediately visible to a human analyst (Hildebrandt and Koops, 2010, p.431-432).

Through apps, websites and even home appliances with the Internet of Things - an emerging technology sector where data collection is ubiquitous (Weber and Weber, 2010, p.1) and 'pervasive' (Matzner, 2014, p.94) - we give up vast amounts of data 
each day to companies to which this data is so valuable, it can become part of their schedule of assets should they become bankrupt (Brunton and Nissenbaum, 2015, p.50).

Algorithms are useful marketing tools because they allow categorisation of users into profiles using big data sets, based on the identification of present preferences and anticipation of future purchasing possibilities (Rouvroy, 2012, p.151). But, there is no need for these profiles to be entirely accurate.

For example, practices of 'real-time bidding', occur within the time it takes to load a webpage (Marshall, 2014). Here, interactions take place between algorithms of a webpage (e.g. a search engine), and those of multiple advertisers (using an intermediary), trading user information through profiles (supposedly linked to a user's interests) and requesting bids for advertisement impressions. This process is automated, taking place in milliseconds, with minimal human involvement, and aims to improve efficiency and reduce budget wastage in the online advertisement industry. But as discussed above, the accuracy of the preferences generated is not a primary concern.

To work from assumptions is enough - as data brokers continue to make profits - while their clients can succeed in promoting their brand through 'impressions', even if the targeted user's interests do not directly align with a specific advertisement. Therefore in this instance, it could be seen as a logical stance for a company to sacrifice the promise of greater accuracy - provided by a more expensive marketing service - in favour of the relatively lower costs of a rival.

Either way, the ability of algorithms to govern activity by directing attention to specific brands - and to shape behavioural patterns of consumption - is on display. It is an autonomic algorithmic market, operating within a German ordoliberal-like formalised framework of 'pure competition' (Foucault, 2008, p.131); a specimen of unabridged efficacy.

Real-time bidding is a process which requires little human intervention, produces quick results, and certain users are likely to be appreciative of it. It is simple and it works. However problems arise when an effort is made to replicate this algorithmic competence, and apply similar market principles to areas which require much more human involvement. For example, credit and insurance companies may use algorithms as a form of financial decision-support, or they may be deployed within the criminal justice system to enable resource and time management programmes.

These are organisations of which the public would expect nothing less than the most stringent of due diligence, before acting upon certain data. Nonetheless, data collection continues, and belief in the objective efficacy of algorithms persists, despite questions 
over accuracy. In the next two sections, this paper will focus on how data is collected, and why algorithms 'work', in turn, before moving towards the use of algorithms in public decision making.

\section{How is big data collected?}

Big data techniques aim to gain the largest sample size possible, thereby dwarfing the levels of traditional data analysis capabilities. Kitchin (2014, p.72) has referred to them as being 'exhaustive in scope' or aiming for ' $n=$ all'.

Exhaustive should be taken to have two further meanings. Firstly, data is a by-product of digital technologies that log transactions, usage, interactions and more, particularly with technologies like the Internet of Things (IOT). The IoT represents the amalgamation of progress in the areas of smart sensors, network technologies and data analytics, by allowing standalone objects such as vehicles become part of wider online assemblages where data is continually exchanged between objects (Stackowiak et al, 2015, p.20). A person's driving patterns could be therefore be recorded and subsumed into a totalised network of connectivity, including smart phone and smart grid data.

Here we see a shift from liberal forms of 'biopolitical' governance, or "politics concerning the administration of life" (Dean, 2010, p.117), meaning that the conduct being 'conducted' is not only that of human life, but also of hardware, software and mechanical vehicles (especially with driverless cars etc.). Notwithstanding this, neoliberal values remain intact, because the results produced can still be used to apply market principles to non-market areas, albeit with an increased focus on behavioural prediction.

The second meaning is that data is often treated as wastage; or as fumes leaving the exhaust to be forgotten about. Privacy policies are accepted without being read, and rights are handed over without due consideration, in order to access 'free' services.

It is estimated that more than one thousand apps are added to Apple's app store every day (Mathew, 2015), and similarly, the Google Play store almost doubled from one million total apps to 1.8 million between July 2013 and November 2015 (Statista, 2016). Many users install a few 'throw-away' apps each week, only to delete them again within a few days. In the meantime, these apps may have been able to harvest a significant amount of personal data through general usage.

Privacy policies usually involve five typical kinds of request, including: location data, camera or media file access, contact information, web history, and access to social 
media interactions such as friend lists, likes and posts (Olmstead and Atkinson, 2015). Not providing these may be a barrier to use.

For a user to simply refuse to use any service asking for egregious permissions is unfortunately no longer a realistic option, because they are engrained in almost all aspects of the online world. Websites use cookies to track visitors, and browsers are tracked by developers and ISPs. Such pervasive tracking should no longer be a surprise, given the incentive for companies to take part in data brokerage. This is now a multibillion dollar industry, and one of the main drivers of the online economy, meaning the higher the volume of data, the better (Kitchin, 2014, p.18). Some may say that it would be silly on their part not to get involved.

Brunton and Nissenbaum (2015, p.59) have compared opting out of such services as a form of digital 'martyrdom'. Digital technologies, are now central tools of contemporary communication, and to isolate oneself from this is a difficult choice. Indeed, to try and make a balanced decision on when to opt in, is almost impossible as users are "uninformed, cognitively overwhelmed, and structurally ill-equipped to manage the vast information and myriad [of] decisions that privacy self-management requires" (Peppet, 2014, p.160).

Even where consent for collection is revoked, this does not bring a retrospective end to the storage of that data in certain jurisdictions. For example the 'Third Party Doctrine' in the U.S. builds from the Supreme Court decision in Katz v. United States (1967) and states that there is "no reasonable expectation of privacy in data held by third parties". There is therefore potentially no redress once a user has provided consent (Jackson et al., p.7). This 'reasonable expectation of privacy' question lies at the heart of US data protection, thus informing and shaping legal interpretation of this issue, in a jurisdiction which represents the main hub of technological innovation for big data (Hildebrandt and Koops, 2010, p.442).

The situation differs significantly in Europe. The upcoming General Data Protection Directive (GDPR) aims to increase user control over the processing of their data, by strengthening consent principles. But, the power of such rules is surely weakened by the impairment of informed choice, which is detrimental to the concept of 'informational selfdetermination' (Noain Sanchez, 2015, p.126).

With all this in mind, collection of personal usage data looks inescapable, unless one takes the famous approach of Henry Thoreau, and abandons society for a secluded cabin. Obviously this is not a realistic option for all, and data collection is a necessary condition for the use of digital technologies. Therefore, it is much more important that 
we are able to understand how it is used, and why it is valued, in order to provide adequate critique.

\section{How does data come to be attributed 'objectivity' and economic value?}

\section{a) Algorithmic Knowledge}

To govern requires knowledge (Miller and Rose, 2008, p.31). Algorithms play a specific part in knowledge production, because of the 'relational' character of big data (Kitchin, 2014 , p.72). The volume of data involved allows correlations between information collected by separate devices, previously difficult to bring together (Peppet, 2014, p.93). This is the crucial point to big data's success, as "its value comes from the patterns that can be derived by making connections between pieces of data, about an individual, about individuals in relation to others, about groups of people, or simply about the structure of information itself" (boyd and Crawford, 2011, p.2). These patterns are constructed through the interpretation of the algorithms involved, and do not need to reflect a universal 'truth' in order to become actionable.

Douglas Merrill, former Google CEO, now runs ZestFinance, a financial services company using big data for credit decisions and has stated, "All data is credit data, we just don't know how to use it yet" (Peppet, 2014, p.27). Such an analysis easily transfers across different sectors because of the 'immediate operationality' of big data techniques (Antoinette Rouvroy, 2012, p.148).

The 'intelligence' of an algorithm is judged upon the efficiency it creates, and the economic fluidity it allows. This is justified by the rationality that an algorithm is merely objectively 'crunching numbers'. However, the public presentation of this process can often obscure its clearly mathematical bases, as is demonstrated by IBM's new 'cognitive business' initiative, adding a human face to the software.

Information is taken to be a "spontaneous germination from digital transcription and the statistical analysis of 'reality'" (Rouvroy, 2012, p.145). 'Reality' should be understood here in the sense used by Boltanski (2011), who contrasts a staged, calculated, form of reality, with the immanence of 'the world' in all its uncertainty (p. 58). This staged reality is constructed through algorithmic technologies that take the world - and its future - as their objects, and reform human (and non-human, with the IoT) potentialities as either programmes to execute or data to capture in turn (Henman, 2010, p.29) - in what Deleuze and Guatarri (1980) would refer to as a rigid "field of overcoding" (p.212). This is done with the hope of making the invisible 'visible' (Lohr, p.2). [1] 
As a result, 'raw' data is taken to be knowledge discovered from the digital world rather than about the digital world (p.146). It becomes equated with the immanence of the 'lived world', thus escaping critique of its calculated origins, and allowing the construction of a subjective (meaning the algorithm's individual interpretation), staged reality; that is washed of this subjectivity when presented publicly. Frameworks of critique and protest become 'inscribed' in "established test formats and qualifications", meaning systematic change becomes much more difficult (Boltanski, 2011, p.32).

It is this characteristic which encourages Rouvroy, to argue that big data is the catalyst for new 'truth regimes' that frame socially acceptable and functional discourse (p.149), after the algorithmic results have been interpreted in such a way so that they fit with particular financial governance goals. This in turn structures the "possible field of action of others" (Lanci, 2015, p.106). Algorithmic interpretation facilitates what Boltanski (2011) refers to as grammars of reality: linguistic and material relations which organise and constitute reality itself. As Miller and Rose (2008, p.31) argue:

The government of a population, a national economy, an enterprise, a family, a child or even oneself becomes possible only through discursive mechanisms that represent the domain to be governed as an intelligible field with its own limits and characteristics, and whose component parts are linked together in some more or less systematic manner.

This 'domain to be governed' is constructed by algorithms through their design, targets, interpretations, and the results they produce; while the 'links' between component parts and discursive mechanisms are established by the discourse of neoliberal (and other) mentalities of government.

Boltanski's definition is particularly useful, as it recognises the fragility of grammars, which can always be critiqued based on the inherent contradictions that arise from their attempt to construct a singular reality. If uncovered, this looks 'arbitrary' in comparison to the immanence of the world.

The complex nature of algorithmic decisions can create significant opacity, leading human actors to take part in 'blind deference' to the machine's decision, due to a belief that the answers they provide a transcendental truth, instead of a subjective one. David Lyon (2014, p.6) specifically uses the term automation to refer to this, by which he means the creation of a 'human-algorithm' relationship where trust is given to the relevant algorithms to establish and interpret correlations in a 'routine' manner.

Influenced by a lack of comprehension of how the algorithm came to a specific conclusion (Zarsky, 2016, p.121), it may not be clear to someone affected by the decision of a credit rating algorithm, for example, that its reasoning could have been 
flawed. The same could be said for a governmental actor allocating public funding based on an algorithmic cost-benefit analysis. Yet, these contradictions remain, and once they are made clear, it becomes difficult to return to this state of 'blindness'.

b) Algorithmic Contradictions

Although big data techniques often set out with the aim of ' $n=a l^{\prime}$ ', the data collected is still inherently a limited sample. It is a process of trial and error (Executive Office of the President, 2016, p. 18). When dealing with economically life-changing decisions such as for credit and insurance, the threat of discrimination is ever-present. Discrimination does not necessarily need to be equated with prejudice based on race, for instance. It could also be entirely unforeseen. To use a slightly frivolous example, an algorithm may decide that all viewers of Better Call Saul, who bought a suit online in the previous year, are lawyers and therefore able to afford higher health insurance, if further data is not available (Lohr, 2015, p.192-195; Sweeney, 2013).

This is because of two typical assumptions underlying algorithmic decision making. Firstly, that initial training samples used for the models will accurately represent the future populations on which these will be applied (particularly in the case of supervised learning), and the second being that any samples taken are a good representation of the population involved (Calders and Zliobaité, 2012, p. 46), meaning that the data obtained is sufficient enough to create a full picture of each connected individual.

Both of these assumptions are susceptible to error and bias, although that is precisely what they are intended to negate. If a large volume of data is collected but incomplete and then acted upon - it is likely to result in unfair practices. When seeking a loan, insurance, or even a job, it is now possible that a person might be scrutinised based upon their data. This can give (possibly flawed) insights into their social interests, attention to personal health, sleep levels, and purchases. In turn, decision-makers may feel that they have enough context to determine the personality of the applicant, and their potential future choices, deeming them an economic risk or not (see Peppet, 2014).

'Usage-based insurance' models are now on the rise (particularly in the UK), most notably fuelled by user data gathered from 'telematic' boxes in cars. Car insurance is a relatively 'inoffensive' testbed for algorithmic analysis, which may later spread to more complex areas such as health insurance - aided by concepts like the 'quantified self' intended to break down one's daily activities and biometric performance into quantities that can be graphically represented, and allow them to be improved upon. [2]

Such decisions are based on normative reasoning and judgments attained from the correlations, and regularities, of 'normal' distribution and deviation of individual conduct. 
The use of data facilitates a process of standardisation, encouraging 'translatability' into qualitative formations, based on perception of measurements and descriptions (Rose, 1991, p.678), which in turn provides economic incentives to those deemed to be 'lowrisk' (i.e careful drivers).

As Danaher (2016) notes, algorithms may not only remove human input from the private sector, but that there is a threat of algocracy - whereby algorithm-based systems could come to "structure and constrain the opportunities for human participation in, and comprehension of, public decision making." (p.245). This is particularly worrying if we are not equipped to adequately critique the numerical bases of algorithmic governmentality, enabled by neoliberal modes of political governance. It is now possible to look how this is beginning to take shape more closely.

\section{Algorithmic government 'at a distance'}

Algorithms can be implemented by any political rationality for governance purposes, which always results in the 'conduct of conduct' - this being the essence of government in Foucault's analysis. But one particular political rationality stands out in relation to algorithms: neoliberal governance. Specifically, algorithms are located in assemblages of what Miller and Rose (2008) refer to as government at a distance.

Miller and Rose use 'government at a distance' to refer to liberal modes of rule characterised by the use of indirect mechanisms that link "calculations at one place to action at another." This is done using a "delicate affiliation of a loose assemblage of agents and agencies" that come to agree that their "problems or goals are intrinsically linked [and] that their interests are consonant" and for this to occur, actors must go through a process of translation in which they become "able to require or count upon a particular way of thinking" (p.34). For liberalism, this 'particular way of thinking', is of the market as a site of 'veridiction', or where truth is spoken (Foucault, 2008, p.56).

Neoliberalism's contribution to this, was to emphasise the "language of enterprise" (Miller and Rose, 2008, p.49) which aims at "possessing the future in advance by objectivising it" (Lanci, 2015, p.102), presenting a choice of alternative and mutually exclusive ends, of which an individual must use their 'scarce means' responsibly to achieve (Robbins, 1935, p.15). This established a dispositif of social debt, fuelled by the 'memory of the future' (Lanci, 2015, p.108), which entails the 'fear of missing out' as well as other traditional conceptions of financial debt - and transferring the responsibility of public debt onto the body social. This economic 'game' is designed to allow automatic indirect government, so as to reduce state intervention. 
This rationality encourages individuals to be 'entrepreneurs' and make use of 'selfknowledge' to construct a "lifestyle through the world of goods" (Miller and Rose, p.49), therefore stimulating market competition - the market itself having become a game of 'non-exclusion' whereby only the minimum protections are required to ensure that "no one player risks losing everything" (Foucault, 2008, p.202). Consequently, the actions of individuals are structured within a field of risk, where each choice and decision can be defined as how financially 'risky' it is.

This 'language of enterprise' has spread beyond the government of individuals, and allowed the market to be bent back upon the state, in what Mitchell Dean (2010) refers to as reflexive government. This refers to the application of neoliberal rationalities of economic risk to areas of social government. He argues that this is achieved through various 'managerial doctrines', which he categorises as technologies of performance including:

Cost of management accounting, the devolution of financial responsibility onto budget units or cost centres, the establishment of quasi-markets, or the various uses of audit are all forms of indirect regulation of other regimes of regulation, whether they be of the school, the hospital, the university, the delivery of home care or child services, as well as of the corporation. (p.225)

This same sentiment was shared by Deleuze (1990, p.4) when he stated that such techniques may express new freedoms, but they could also come to "participate in new mechanisms of control that are equal to the harshest of confinements" through the "closure of the future", and the capitalist annexation of time (Lanci, 2015, p.112).

The plasticity of neoliberalism allows any object to become captured in this apparatus, since it "both feeds on and reproduces the moods of populations" (Fisher, 2009, p.36). As stated, it does not require a transcendental truth or a specific end goal to function, other than the translation of social relations and government into numbers, and subsequently into the language of the market. Therefore, neoliberal algorithmic governmentality does produce the "subjects it needs" (contra Rouvroy, 2012, p.151), because it only requires those subjects to participate in the market - with a modicum of self-knowledge - whether accurate or not.

This can, and has, affected many areas of public governance, but this paper focuses on the law. Whilst we have not seen a truly neoliberal court, yet, it is possible to speak of the ways in which algorithmic government is pushing things in this direction. We can see this in terms of the reconfiguration of certain legal processes, including changes to legal knowledge construction, the subsumption of legal actors into algorithmic operations, and the introduction of new technologies to facilitate the automation of various workloads. For example, the American criminal justice system is gradually being transformed into an 
experimental laboratory for algorithmic governmentality. There are two excellent and alarming examples of this, both of which involve an appraisal of future potentialities.

In a report drawn up by the Executive Office of the President (2016, p.19-22), numerous allusions are made to the adoption of 'predictive policing' in a various states across the US. These aim to "identify patterns in criminal activity in order to allocate scarce resources more efficiently" through the use of algorithmic analysis. Such programmes are already in action, yet the report acknowledges both that "criminal justice data is notoriously poor" - because it is often inherently subjective - and that the use of historical information has the potential to "perpetuate policing practices that are not sufficiently attuned to community needs." The expectation of such programs is that having officers at the "proposed place and time will deter or detect criminal activity" (Ratcliffe, 2015)

When dealing with big data, the notion of not being 'sufficiently attuned to community needs' softens the blow of the real threat, in that it could perpetuate already existing discrimination, as discussed earlier. Predictive policing is being trialled by the LAPD, a force notorious for previous accusations of racial bias. To begin a trial in an already contentious area like this - using questionable historical data, that breaches both assumptions referred to above - demonstrates that preference is given to resource and time management, and therefore market-based reasoning, in place of due critique. Should repurposed user data from technologies like the Internet of Things be added into the (already flawed) mix, matters are likely to become even more complex.

Algorithms are also being used for risk assessment in U.S. courts. In Broward County, Florida, the task of assessing risk has been outsourced to Northpointe, a private company providing decision support to multiple local criminal justice systems across the USA. A study by ProPublica has revealed that mistakes were made on the assessment of both white and black defendants - aiming to predict future crimes within two years after the assessment, a benchmark set by the company itself - but with a clear disparity. Black defendants were wrongly identified as future criminals "at almost twice the rate as white defendants" and white defendants "were mislabelled as low risk more often than black defendants" (Angwin et al., 2016). Identification as high-risk can lead to increased bail bonds and sentences. Section 203 of the Sentencing Reform and Corrections Act of 2015 (awaiting approval of the Senate at time of writing) legislates for a similar, singular, 'Post-Sentencing Risk and Needs Assessment System' to be implemented across the United States.

Northpointe refuses to disclose the method of calculation, but the score derives from 137 questions, none of them include queries on race. Once again, resource management and 
efficiency are the driving goals, at the expense of due process (Northpointe's software reportedly costs a measly $\$ 22,000$ a year). Here, not only has data been adapted from a third party, but that same party has become an arm of the justice system itself, in a process of privatisation that implements neoliberal government at a distance.

If algorithms are beginning to take their place as the providers of quasi-expert testimony in the courtroom, does that in itself represent a warning shot for the coming shift in how the law operates? Algorithms are security mechanisms in that, among other things, they determine the progression of phenomena "within acceptable limits and around an average that will be considered optimal for social functioning" - delimited by 'risk' (Foucault, 2007, p.5; p.66). But, if they are merely perpetuating pre-existing biases within the system, albeit more efficiently by bypassing socio-legal critique, should that really be considered socially acceptable? Is it the economic 'operationality' that is defining these 'acceptable' limits? How can legal actors ensure due process and critique?

\section{The 'ghost' in the legal machine}

As argued by Morison and Leith (1992), legal knowledge is: "a process, not a corpus"; strategic and negotiable"; a dialogic one where "timetables are brought to bear", and that courts require "truth within given times" (p.195); meaning the best kind of legal point is the "one that works", and gets the job done persuasively and efficiently (p.95).

Having explored the examples above, algorithms are clearly attractive to law, because they can reduce the time needed to close cases. But the 'persuasive' element is also crucial, as it touches directly upon the law's specific performance as a 'truth regime'; requiring arrival at an acceptable 'truth', in the knowledge that the established 'facts' were negotiated at the same time as the applicable rules, and as part of a highly social process (p.78). Objective facts are not always needed, or even desired, as is demonstrated by subjective tests in UK criminal law. For example in R v Owino [1996] 2 $\mathrm{Cr}$ App R 128, it was established that (objectively) reasonable force for self-defence is permitted in the circumstances, as the defendant subjectively believes them to be. To obtain these insights, information is required, and technology changes how this information is collected and treated.

A norm-setting reciprocity or 'modulation' exists between digital technologies and social institutions, like that of law, meaning the legal system continually mutates to meet particular needs of our new digital society, and vice versa (Deleuze, 1992, p.4). Having invented these new technologies, they in turn '(re)invent' us (Hildebrandt, 2015, p.28), 
whether this was the initial purpose or not. Or, in the language of governmentality, the conduct of one governmental technology mutates to suit the conduct of the other.

As attested by McGinnis and Wasick (2010, p.993), law is an information technology itself, facilitating the flow of information from the governing to the governed, and from the governed to the governing, as it "incorporates new data from legal disputes". They make the point that "the nature of legal [knowledge] production depends on the technology of its age" and give the example of computerised document searches and organisation, now standard in litigation proceedings, because of the ever increasing volume of digital documents or 'electronically stored information' (ESI) (p.1000).

This is currently moving towards the next step - as demonstrated by the automation of paralegal work - using artificial intelligence programmes like ROSS, a re-purposed version of IBM's Watson for document discovery. If you "ask direct questions", ROSS will "find you answers from the law in seconds" and it is also hoped that it will help "craft and practice oral arguments" in the future. [3]

While the potential of ROSS is speculative for now, algorithmic analysis is already increasingly a more important type of expertise in the world of litigation, as it can provide insights on judiciary behaviour, 'timing analytics' for courts, and the legal history of opposing counsel, witnesses, and even represented parties (Dysart, 2013; Dixon, 2016).

There are two interlinking rationalities for incorporating such technologies into the world of law. Firstly, they enable processes of financial risk management that allows: case selection procedures to weed out those that are more 'risky', cost reduction for firms in litigation procedures, the automation of tedious research normally reserved for entrylevel positions, thus reducing labour costs, and ultimately reducing the time needed to build a legal argument. Every firm and individual justice system therefore acts with the entrepreneurial spirit that neoliberalism so values, organised around the language of enterprise, in ways almost no different to the examples of targeted advertising mentioned above. This leads to the second point: that algorithms also increase the 'persuasiveness' of legal arguments, because they approach the construction of legal knowledge in novel ways.

Algorithms are, in a sense, the perfect witness (if involved in advocacy, and the knowledge produced suits your argument). Big data makes use of the ubiquitous and pervasive data collection of smart technologies; and its 'relational' character can facilitate the 'telling of a story' by building a persuasive, 'immediately operational' narrative that stages a form of reality - amongst the drama of case-building and the 
theatre of the courtroom. Correlations between different data sources can be used to establish locations, interests, intentions, and more (Jackson et al., 2017, p.7). Whether this is accurate is almost irrelevant so long as it persuades, as an algorithmic confessor in the battle for production of 'truth', within a legal investigation (Foucault, 1995, p.41).

There are numerous ethical issues ready to be unpacked here, especially as this data was collected for different purposes. However, in a way, this is not so far from the common practice of private email disclosure in litigation procedures, which only a few years ago would have been looked at in the same way. It also begs the (speculative) question as to whether this information could be used to determine guilt through risk profiles (presenting probabilities by percentage) in the future. After all, if the standard civil burden of proof in Anglo-American civil cases is on the balance of probabilities or "more probable than not" as Lord Denning put it in Miller v Minister of Pensions [1947] 2 All ER 372, wouldn't an algorithmic risk profile suit this perfectly? Perhaps, but it may also be a catalyst for direct translation with economic calculations, and therefore it further widens the scope for neoliberal risk management strategies of government, that are already taking hold of legal systems.

Looking at this through the lens of neoliberal rationality however, it is the economics which take precedence. Algorithmic results therefore also persuade legal actors to use such technologies, within the financially risky game of legal practice, because they can focus upon material and financial concerns, providing solutions that 'work' and 'get things done' efficiently. The conduct of legal actors is conducted by economic 'grids of intelligibility' which may tease out new knowledge(s) from the world, but in doing so they necessarily filter out other potentialities (Foucault, 2003, p.226).

There are various ways by which big data can become involved in a case. In UK civil cases, each party must disclose electronic information "on which he relies", that which "adversely affects" their own or another party's case, and that which will "support" another party's case. There is also a requirement for a "reasonable" search to be made for any relevant documents (Civil Procedure Rules, sections 31.6 and 31.7). In a UK criminal case, a defendant may choose to disclose a defence statement or alibi, which could include big data analytics (under section 6 of the Criminal Procedure and Investigations Act 1996). This could be the case if the defendant wants to bring a level of 'objectivity' to the subjective tests mentioned above. Concepts of privacy and personal data take a backseat here, in a process where relevance is the deciding factor. [4]

As famously stated by Holmes (1923):

The life of the law has not been logic: it has been experience. The felt necessity of the time; the prevalent moral and political theories, intuitions of public policy, avowed or unconscious; even the 
prejudices which judges share with their fellow-men, have had a good deal more to do than the syllogism in determining the rules by which men should be governed. The law embodies the story of a nation's development through many centuries, and it cannot be dealt with as if it contained only the axioms and corollaries of a book of mathematics. (p.1)

The law is a highly social process; not deterministic, but prone to accident, and capable of producing unintended effects. The only guaranteed ever-present characteristic in legal practice is the productive power of creativity, employed to satisfy the 'felt necessities' described above (Lefebvre, 2009, p.39). This is productive in the sense that it produces social norms, or 'common denominators' through the imposition of "purpose" over texts, data and traditions, by which an individual can evaluate one's actions, or those of others (Ewald, 1990, p.152; Dworkin, 1986, p.228).

We are at a point in algorithmic technology where it is possible to guide its use before "closure and stabilisation limit debate" on the subject (Ananny, 2016, p.97). Developing technologies often succumb to a 'lock-in' (Lanier, 2010, p.7), whereby one particular design or method of operation becomes standard. Big data has the potential though to create legal lock-in supported by a powerful truth regime with a 'common-sense' and 'objective' approach (Kitchin, 2014, p.113); and enforced by a system of strong precedent, as "judges normally recognise a duty to continue rather than discard the practice they have joined" (Dworkin, 1986, p.87).

The law is itself a technology of liberal government, ensuring the "existence and practice of economic freedom" (Foucault, 2008, p.86), and it 'conducts conduct' as a result. If legal actors want the law to be viewed as a respectable institution that provides social justice, they must consider the use of algorithms and big data with creative critique; looking beyond the statistics of economic performance, and the effectiveness of an algorithmic argument (granted, this is much easier said than done). Algorithmic evidence does not only improve an argument, but it also adds to the increasing indiscriminate quantification and metamorphosis of the 'lived world' into the staged reality of neoliberal economics. Such critique could even manifest itself as: an advocate choosing to appease an opposition counsel's attempts at using algorithmic evidence, if only to pick apart its accuracy in trial. Whatever happens, the legal future is luckily not yet determined.

\section{Conclusions}

Both algorithms and the law are instruments of government, able to implement political rationalities and organise the 'conduct of conduct'. Because of this characteristic, as technologies, the ways in which they can be used are not pre-determined, meaning they 
are susceptible to mutation by a variety of actors. Neoliberal economics and risk management strategies are now riding the wave of this malleability in both areas, which as has been shown, are ever more likely to work in tandem. This partnership works because both the law and algorithms work within assemblages of knowledge discovery that come to accepted agreements and particular presentations of 'truth' as a basis for action. They can on the other hand have determinative effects, by shifting power relations with normative force, both intentionally and unintentionally. Given that both can produce detrimental economic or legal effects for a person who has been incorrectly profiled, creative critique is vital, so as to point out any existing contradictions or inaccuracies of the accepted reality.

This paper has clearly dealt with very conceptual and theoretical issues, which although it allows exploration of the pertinent topics at an abstract level, it is mainly informed by the relevant literature and public-facing descriptions of various technologies in development, along with limited personal employment within e-discovery for large-scale commercial disputes. However this is conceptual style is intended, as a basis for future research in the hope that this will be the starting point for ethnographic research into algorithmic and legal practices - so as to gain a greater insight into the motivations of those who are directly involved in the day-to-day operation of these governmental technologies. This could involve talking to lawyers, judges, administrators, developers, or even defendants that have gone through these processes.

\section{Notes}

1. E.g. Watson is said to act 'cognitively', 'think' for itself, and to discover the 'dark data' of businesses: https://www.ibm.com/cognitive/outthink/ (Accessed: 01/02/2017)

2. Research statistics from the British Insurance Brokers' Association (BIBA) available at: https://www.biba.org.uk/press-releases/40-increase-in-telematics-motor-policies-ina-year/ (Accessed: 01/02/2017)

3. Whitepaper available at: http://www.rossintelligence.com (Accessed: 16/01/2017)

4. McLeod Law, a Canadian firm, have used Fitbit analytics, to support a client's claims stating that it "closes the gap between what a client perceives and what is objectively verifiable": http://www.mcleod-law.com/news/vivametricas-analytics-platform-supportspersonal-injury-claims (Accessed: 01/02/2017)

\section{Bibliography}


Ananny M. (2016) "Toward an ethics of algorithms: convening, observation, probability, and timeliness", Science, Technology \& Human Values, 41(1), pp. 93-117.

Angwin, J., Larson, J., Mattu, S., Kirchner, L. (2016) "Machine bias: There's software used across the country to predict future criminals. And it's biased against blacks", Available at: https://www.propublica.org/article/machine-bias-riskassessments-in-criminal-sentencing (Accessed: 01/02/2017).

Boltanski, L. (2011) On critique: A sociology of emancipation, Cambridge: Polity Press.

Boyd, d. and Crawford, K. (2011) "Six provocations for big data" (September 21, 2011) paper presented at A Decade in Internet Time: Symposium on the Dynamics of the Internet and Society, September 2011. Available at: http://ssrn.com/abstract $=1926431$ (Accessed: 01/02/2017)

Brunton, F. and Nissenbaum, H. (2015) Obfuscation: A User's Guide For Privacy and Protest, MIT Press, Cambridge.

Calders, T. and Žliobaitè, I. (2013) "Why unbiased computation processes can lead to discriminative decision procedures", in Custers, B., Calders, T., Schermer, B., Zarsky, T. (ed.) Discrimination and Privacy in the Information Society: Data Mining and Profiling in Large Databases. Berlin: Springer, pp. 43-57.

Danaher, J. (2016) "The threat of algocracy: Reality, resistance and accommodation", Philosophy \& Technology, 29(3), pp. 245-268.

Dean, M. (2010) Governmentality: Power and Rule in Modern society, London: SAGE.

Deleuze, G. (1992) "Postscript on the societies of control", October, 59, pp. 3-7.

Deleuze, G and Guatarri, F. (1980) A Thousand Plateaus: Capitalism and Schizophrenia, Minneapolis: University of Minneapolis Press.

Dixon, J. (2016) 'Review of Legal Analytics Platform ', LitigationWorld [Online]. Available at: https://lexmachina.com/wp-content/uploads/2016/10/LitigationWorld-Review2016. pdf (Accessed: 16/01/2017).

Dworkin, R. (1986) Law's Empire, Hart Publishing, Oxford.

Dysart, J. (2013) How lawyers are mining the information mother lode for pricing, practice tips and predictions, Available at: http://www.abajournal.com/magazine/article/the_dawn_of_big_data/?utm_source=f eedburner\&utm_medium =feed\&utm_campaign=ABA+J ournal+Magazine+Stories (Access ed: $01 / 02 / 2017)$.

Ewald, F. (1990) "Norms, discipline and the law", Representations, 30 (Spring), pp. 139161.

Executive Office of the President (2016) "Big data: A report on algorithmic systems, opportunity, and civil rights", Available at:

https://www.whitehouse.gov/sites/default/files/microsites/ostp/2016_0504_data_discri mination.pdf (Accessed: 01/02/2017)

Foucault, M. (1995) Discipline and punish: The birth of the prison, 2nd edn., New York: Vintage.

Foucault, M. (2007) Security, Territory, Population: Lectures at the College de France 1977-78, New York: Palgrave Macmillan. 
Foucault, M. (2003) Society must be defended: Lectures at the College de France 19751976, New York: Picador.

Foucault, M. (2008) The Birth of Biopolitics: Lectures at the College de France 1978-79, New York: Palgrave MacMillan.

Henman, P. (2010) Governing Electronically: E-Government and the Reconfiguration of Public Administration, Policy and Power, New York: Palgrave Macmillan.

Hildebrandt, M. (2015) Smart Technologies and the End(s) of Law, Edward Elgar, Cheltenham.

Hildebrandt, M. and Koops B.J. (2010) "The challenges of ambient Law and legal protection in the profiling era", Modern Law Review, 73(3), pp. 428-460.

Holmes, O.W. (1923) The Common Law, 3rd edn., Boston: Little, Brown and Company.

Jackson, B.A., Banks, D., Woods, D., Dawson, J.C. (2017) Future-proofing justice: Building a research agenda to address the effects of technological change on the protection of constitutional rights, RAND Corporation [Online] Available at: http://www.rand.org/pubs/research_reports/RR1748.html (Accessed: 01/02/2017)

Kitchin, R. (2014) The Data Revolution: Big Data, Open Data, Data Infrastructures \& Their Consequences, Sage Publications, London.

Lefebvre, A. (2009) 'The time of law: Evolution in Holmes and Bergson', in Braidotti, R., Colebrook, C., Hanafin, P. (ed.) Deleuze and Law: Forensic Futures. New York: Palgrave Macmillan, pp. 24-46.

Lanci, Y. (2015) 'Remember tomorrow: Biopolitics of time in the early works of Philip K. Dick ', in Dunst, A., Schlensag, S. (ed.) The World According to Philip K. Dick. New York: Palgrave Macmillan, pp. 100-118.

Lohr, S. (2015) Data-ism: Inside the Big Data Revolution, Oneworld Publications, London.

Lyon, D. (2014) "Surveillance, Snowden, and big data: Capacities, consequences, critique", Big Data \& Society, Jul 2014 1(2) [Online]. Available at: http://bds.sagepub.com/content/1/2/2053951714541861 (Accessed: 01/02/2017).

Marshall, J. (2014) "WTF is real time bidding?" Available at: http://digiday.com/platforms/what-is-real-time-bidding/ (Accessed: 01/02/2017)

Mathew, J. (2015) "Apple App Store growing by over 1,000 apps per day", Available at: http://www.ibtimes.co.uk/apple-app-store-growing-by-over-1000-apps-per-day-150480 (Accessed: 01/02/2017).

Matzner, T. (2014) "Why privacy is not enough privacy in the context of "ubiquitous computing" and "big data"'", Journal of Information, Communication and Ethics in Society, 12(2), pp. 93-106.

McGinnis, J. and Wasick S. (2014) "Law's algorithm", Florida Law Review, 66(12-22), pp. 991-1050.

Miller, P. and Rose, N. (2008) Governing the Present: Administering Economic, Social and Personal life, Cambridge: Polity Press.

Morison, J. and Leith, P. (1992) The Barrister's World and the Nature of Law, Buckingham: Open University Press. 
Noain-Sánchez, A. (2016) "'Privacy by default" and active "informed consent" by layers Essential measures to protect ICT users' privacy", Journal of Information, Communication and Ethics in Society, 14(2), pp. 124-138

Olmstead, K. and Atkinson, M. (2015) "Apps permissions in the Google Play store", Available at: http://www.pewinternet.org/2015/11/10/apps-permissions-in-the-googleplay-store/ (Accessed: 01/02/2017).

Peppet, S. R. (2014) "Regulating the Internet of Things: First steps toward managing discrimination, privacy, security, and consent", Texas Law Review, 93(1), pp. 85-175.

Ratcliffe, J. (2015) "What Is the Future... of Predictive Policing" available at: https://www.academia.edu/26606550/What_Is_the_Future_of_Predictive_Policing (Accessed: 01/02/2017).

Robbins, L. (1935) An Essay on the Nature \& Significance of Economic Science, 2nd edn., London: Macmillan.

Rose, N. (1991) "Governing by numbers: Figuring out democracy", Accounting Organisations and Society, 16(7), pp. 673-692.

Rose, N. (1999) Powers of Freedom: Reframing Political Thought, Cambridge University Press, Cambridge.

Rouvroy, A. (2012) "The end(s) of critique: data-behaviourism vs. due-process", in Hildebrandt, M. and De Vries, E. (ed.) Privacy, Due process and the Computational Turn. Philosophers of Law Meet Philosophers of Technology. Abingdon: Routledge, pp. 143.

Schneier, B. (2015) Data and Goliath: The Hidden Battles to Collect Your Data and Control Your World, W. W. Norton, New York.

Stackowiak, R., Licht, A., Mantha, V., Nagode, L. (2015) Big Data and The Internet of Things: Enterprise Information Architecture for a New Age, Apress, Berkeley.

Statista (2015) "Number of available applications in the Google Play Store from December 2009 to November 2015", Available at: http://www.statista.com/statistics/266210/number-of-available-applications-in-thegoogle-play-store/ (Accessed: 01/02/2017).

Sweeney, L. (2013) "Google ads, black names and white names, racial discrimination, and click advertising", ACMQueue, 11(3), pp. 1-19.

Weber, R.H. and Weber, R. (2010) Internet of Things: Legal Perspectives, Springer, Berlin.

Winner, L. (1986) The Whale and the Reactor: A Search for Limits In An Age of High Technology, Chicago University Press, Chicago.

Zarsky, T (2016) "The trouble with algorithmic decisions: An analytic road map to examine efficiency and fairness in automated and opaque decision making", Science, Technology and Human Values, 41(1), pp. 118-132. 
